\title{
Neurotoxicity and Neuroinflammatory Effects of Bisphenol A in Male Rats. The Neuroprotective Role of Grape Seeds Proanthocyanidins
}

Saber Mohamed Eweda ( $\sim$ seweda@taibahu.edu.sa )

Taibah University https://orcid.org/0000-0002-5151-0137

Heba M. Abdou

Alexandria University

Heba-Tallah Abd Elrahim Abd Elkader

Alexandria University

Amel H. El-Gendy

Alexandria University

\section{Research Article}

Keywords: Bisphenol A, Grape seed proanthocyanidins, oxidative stress, Na/K-ATPase, TNF-a, COX-2

Posted Date: June 8th, 2021

DOI: https://doi.org/10.21203/rs.3.rs-544366/v1

License: (c) (i) This work is licensed under a Creative Commons Attribution 4.0 International License. Read Full License 


\section{Abstract}

Exposure to bisphenol A (BPA) contributes to neurological disorders, but the underlying mechanisms are still not completely understood. We studied the neurotoxic effect of BPA and how it promotes inflammation and alteration in the neurotransmission synthesis, release and transmission. This study was also designed to investigate the neuroprotective effect of grape seed proanthocyanidins (GSPE) against BPA-induced neurotoxicity in rats. Rats were equally divided into 4 group with 7 rats in each as follows: control group, BPA group, GSPE + BPA group and GSPE group. Rats were orally treated with their respective doses (50 mg BPA/kg BW and/or $200 \mathrm{mg} \mathrm{GSPE} / \mathrm{kg} \mathrm{BW}$ ) daily for 70 days. BPA elicits significant elevation in malondialdehyde (MDA) and nitric oxide (NO) associated with significant reduction in glutathione (GSH), total thiols, glutathione peroxidase (GPx), superoxide dismutase (SOD) and glutathione-S-transferase (GST). BPA exposure result in increased dopamine and serotonin levels, elevation in acetylcholine esterase (AchE) activity and reduction in Na/K-ATPase and total ATPase activities in the brain. Also, BPA induces upregulation in the gene expression of the inflammatory markers; tumor necrosis factor- $a$ (TNF-a) and cyclooxygenase-2 (COX-2), and in the tumor suppressor and prooxidant p53 protein. The pretreatment with GSPE attenuate or ameliorate all the oxidative and neurotoxic parameters induced by BPA. Our results suggest that GSPE has a promising role in modulating BPAinduced neuroinflammation and neurotoxicity and its antioxidant and free radical scavenging activities may in part be responsible for such effects.

\section{Introduction}

The exposure to neurotoxic compounds induce over production of reactive oxygen species (ROS) and reactive nitrogen species (RNS) which play a crucial role in neurodegenerative disorders by oxidizing proteins, DNA and lipids of neuronal cells leading to pathways for cell death (Zhao et al. 2019). The chronic exposure to neurotoxic substances from environment or from ingestion of food trigger inflammatory process in the brain contributing to cognitive impairment and neurodegenerative diseases, including, Alzheimer's disease (AD) and Parkinson's disease (PD) (Niranjan 2018). Exposure of humans to bisphenol A (BPA) has been a matter of concern due to its increased usage in the products of day to day use. High amounts of BPA used in the production of polycarbonate plastics and epoxy resins which used in food and beverages packaging, electronic devices, optical storage discs, construction material, dental sealants and thermal printing paper (Raisuddin \&Sharma 2017). BPA monomers can leach-out from these products, when subjected to washing processes, heating or contact with acidic or basic $\mathrm{pH}$, and enter human body through occupational and food contact (Musachio et al. 2020). BPA has been linked with multiple neuropsychological disorders and neurobehavioral disturbances due to its ability to pass through blood-brain barrier (Resnik \&Elliott 2015). It has been reported that BPA causes neurological injury by damaging protein and lipid structures through free radicals mediated mechanisms (Agarwal et al. 2016). The prenatal exposure to BPA was related to adverse impacts of behaviours and cognitive abilities at children's early life, such as social response and working memory (Braun et al. 2017). 
The bioactive compounds from natural sources have been attracting growing attention in recent decades. Phytochemicals, as polyphenols, in fruit, vegetables and medicinal plants have a wide range of healthprotective effects on heart, kidney, liver and brain (Nassiri-Asl \&Hosseinzadeh 2009). Grape seeds are one of the richest sources of polyphenols; monomeric flavan-3-ols, phenolic acids and oligomeric proanthocyanidins (Prasain et al. 2009). Proanthocyanidins from grape seeds contain complex pool of polyphenolic compounds mainly catechin monomers, or their dimers, trimers, and oligomers, which are otherwise known as tannins (Zhang et al. 2015). Grape seeds proanthocyanidins (GSPE) are superior radical's scavenger over vitamins $\mathrm{C}, \mathrm{E}$ and carotene. It protects liver and brain against lipid peroxidation and DNA damage, has antidiabetic, antibacterial, anticancer and antiinflammatory effects (Shan et al. 2010). It has been revealed that GSPE induce protective effects against brain damage via their chelating ability and antioxidant properties (Chu et al. 2014). GSPE protect against depression and age-related mental deterioration by inducing hypothalamic-pituitary-adrenal axis action and hippocampal neurogenesis (Sutcliffe et al. 2017).

Despite the role of BPA in neurotoxicity and neuronal damage have been targeted by several researches over the years, the underlying mechanisms by which BPA induces neurotoxicity and neurodegenerative disorders still need to be further elucidated. The present study aimed to investigate the neurotoxic effects of BPA on brain tissue that may be a cause for neuronal damage and neurodegenerative diseases. Also, the study investigates the possible neuroprotective effects of GSPE on BPA-induced oxidative stress, neuroinflammation and neurotoxicity in rats' brain.

\section{Materials And Methods}

\section{Reagents}

Bisphenol A 98\% purity in the form of white crystals was purchased from Loba Chemie for laboratory reagents and fine chemicals (India). Grape seed proanthocyanidins was purchased from Arab company for pharmaceuticals and medicinal plants (MEPACO-MEDIFOOD, Enshas- El Raml, Sharkeya, EGYPT). Reduced glutathione (GSH), glutathione reductase (GR), 2-thiobarbituric acid, pyrogallol, NADPH, bovine serum albumin and 1,1,3,3-tetraethoxypropane, 5,5'-dithiobis-(2-nitrobenzoic acid) (DTNB) were purchased from Sigma-Aldrich (Merck KGaA, USA). All other chemicals and kits were of analytical grade.

\section{Animals and experimental design}

Twenty-eight adult male Wister albino rats (weight, 120-130 g) were obtained from the animal house of Faculty of Medicine, Alexandria University, Alexandria, Egypt. Rats were housed in stainless steel cages and provided with a basal diet and tap water ad libitum. Rats were maintained under $50-60 \%$ relative humidity and $25 \pm 5^{\circ} \mathrm{C}$ with a $12 \mathrm{~h}$ light/dark cycle during the experimental period. After two weeks of acclimatization, rats were randomly and equally divided into four equal groups with 7 rats in each as follows: control group received $0.5 \mathrm{ml}$ distilled water and 0.5 corn oil, BPA-group was treated with $0.5 \mathrm{ml}$ BPA at a dose of $50 \mathrm{mg} / \mathrm{kg}$ BW/day dissolved in corn oil (Tyl et al. 2002), GSPE + BPA group received 0.5 
$\mathrm{ml} \mathrm{GSPE}$ at a dose $200 \mathrm{mg} / \mathrm{kg} \mathrm{BW} /$ day dissolved in distilled water (Yousef et al. 2009) and $0.5 \mathrm{ml} \mathrm{BPA}$ at a dose $50 \mathrm{mg} / \mathrm{kg} \mathrm{BW/day,} \mathrm{and} \mathrm{GSPE-group} \mathrm{which} \mathrm{treated} \mathrm{with} 200 \mathrm{mg} / \mathrm{kg} \mathrm{BW/day} \mathrm{GSPE} \mathrm{dissolved} \mathrm{in} 0.5$ distilled water. During the experimental period, GSPE was given 30 min before BPA administration and doses were given once daily via gavage for 70 consecutive days. The design and experimental techniques of the current study were approved by the Institutional Animal Care and Use Committee (IACUC) of Alexandria University in accordance with the guidelines of the National Institutes of Health Guide for the Care and Use of Laboratory Animals. All efforts were made to minimise the suffering of rats during the experimental period.

\section{Blood sampling and tissue preparation}

At the end of experimental period, rats were deeply euthanized via an intraperitoneal injection of 100 $\mathrm{mg} / \mathrm{kg}$ ketamine and $20 \mathrm{mg} / \mathrm{kg}$ xylazine after a starvation period of $12 \mathrm{~h}$. four $\mathrm{ml}$ of blood was obtained through cardiac puncture using a sterile syringe. Death was subsequently confirmed by the inhalation of $\mathrm{CO}_{2}$ followed by cervical dislocation. Serum was obtained by centrifugation of clotted blood at $1000 \mathrm{xg}$ and $25^{\circ} \mathrm{C}$ for $10 \mathrm{~min}$ and kept at $20^{\circ} \mathrm{C}$ for lipid profiling tests. Brain was immediately excised, washed using chilled saline solution and the adhering fat and connective tissues were removed. Parts of the brain tissues were immediately

removed and kept at $-80^{\circ} \mathrm{C}$ for molecular analysis. Another parts of brain were minced and homogenized $(10 \%, w / v)$ in ice-cold phosphate buffer $(0.01 \mathrm{M}, \mathrm{pH} 7.4)$ containing $1.15 \% \mathrm{KCl}$. The homogenates were centrifuged at $10000 \times \mathrm{g}$ for 20 min at $4^{\circ} \mathrm{C}$ (Hitachi Ltd.; model, EBA 12R). Supernatants were stored in aliquots of $1 \mathrm{ml}$ at $80^{\circ} \mathrm{C}$ for subsequent biochemical analysis.

\section{Determination of oxidative stress biomarkers in brain tissue}

Lipid peroxidation end product (malondialdehyde, MDA) was measured in brain tissue as thiobarbituric acid reactive substances (TBARS) at $532 \mathrm{~nm}$ using 2-thiobarbituric acid and expressed as $\mathrm{nmol} \mathrm{MDA} / \mathrm{g}$ tissue (Draper \&Hadley 1990). Nitric oxide (NO) concentration in brain supernatant was measured by commercial kit purchased from Biodiagnostic Co. Cairo, Egypt. The reaction based on simple Griess reaction according to the method of (Guevara et al. 1998).

\section{Determination of enzymatic antioxidants and detoxificants activities in brain tissues}

Total glutathione peroxidase (GPx) activity was measured using cumene hydroperoxide as a substrate by the method of (Flohe \&Günzler 1984). The assay method based on monitoring the generation of GSH from GSSG by the action of glutathione reductase in presence of NADPH. The activity of superoxide dismutase (SOD) was determined according to the method of (Marklund \&Marklund 1974). The method depends on inhibition of spontaneous autoxidation of pyrogallol at alkaline $\mathrm{pH}$ by removal of superoxide anion radicals using SOD in the sample. Autoxidation was monitored as an increase in absorbance at 
$420 \mathrm{~nm}$. The total activity of glutathione-S-transferase (GST) was assayed by the method of (Habig et al. 1974). Optical density was measured at $340 \mathrm{~nm}$.

\section{Determination of non-enzymatic antioxidants in brain tissues}

Reduced GSH was determined in supernatant of brain tissue using NADPH as a reducing agent and dependent on oxidation of GSH by 5,5- dithiobis (2-nitrobenzoic acid) (DTNB) as previously described (Griffith 1980). Total thiol content of brain tissue supernatant was carried out as described previously (Sedlak \&Lindsay 1968).

\section{Measurement of serum lipid profile}

The serum levels of triglycerides (TG), total cholesterol (TC), low density lipoprotein cholesterol (LDL) and high-density lipoprotein cholesterol (HDL-C) were measured by commercially available diagnostic kits from Biosystems S.A (Biosystems S.A. Costa Brava 30, Barcelona, Spain).

\section{Determination of protein content}

The protein content of brain tissue supernatant was determined by the method of Lowry using folinciocalteu reagent and bovine serum albumin as a standard (Lowry et al. 1951).

\section{Determination of neuro-specific biomarkers}

Acetyl cholinesterase (AChE) activity was assayed in brain tissue using the method of (Ellman et al. 1961). The activity of AChE was calculated as nmoles of hydrolyzed acetylthiocholine iodide $/ \mathrm{min} / \mathrm{mg}$ protein using molar extinction coefficient of $1.36 \times 104 \mathrm{M}^{-1} \mathrm{~cm}^{-1}$. The specific activity of total ATPase activity in brain supernatant was assayed using ELISA kit purchased from ImmunoWay Biotechnology Company (USA). Brain $\mathrm{Na}^{+}-\mathrm{K}^{+} /$ATPase specific activity was assayed according to the manual instructions of ELISA kit purchased from MyBioSource (USA). The activities of both total APTase and $\mathrm{Na}^{+} / \mathrm{K}^{+}$-ATPase were expressed as $\mu \mathrm{mol} / \mathrm{min} / \mathrm{mg}$ protein. Dopamine (DA) and serotonin levels in brain were measured using sandwich technique of Solid phase ELISA kits for the in vitro quantitative measurement purchased from Gen Way Biotech (San Diego, USA).

\section{Molecular analysis and gene expression of p53, c0X-2 and TNF-a}

Parts of brain tissues were kept in RNA later for immediate stabilization. Total RNA was extracted from brain tissues using Biozol RNA Isolation Kit. The RNA extract was re-suspended in $100 \mu \mathrm{L}$ RNase-free $\mathrm{H}_{2} \mathrm{O}$. The purity of the RNA preparation was estimated to be 1.8-2.0 according to the ratio of absorbance at $260 \mathrm{~nm}$ and $280 \mathrm{~nm}$ [Abs 260/Abs 280]. RNA concentration was determined using the following equation: 1 absorbance unit at $260 \mathrm{~nm}$ corresponds to approximate concentration of $40 \mu \mathrm{g} / \mathrm{mL}$ of singlestranded RNA (Chomczynski \&Sacchi 2006). Alteration in the neuro-inflammatory markers; tumour necrosis factor-a (TNF-a), cyolooxygenase-2 (COX-2) and p53 mRNAs gene expression levels were 
determined using reverse-transcriptase PCR analysis. One-step Maxime RT-PCR premix Kit reaction was used for the cDNA synthesis and for amplification of target genes using the following specific primer sets;

TNF-a (Accession number: NM_012675.3);

Forward: 5'-GCACAGAAAGCATGATCCGA-3'

Reverse: 5'-CCTGGTATGAAGTGGCAAAT-3'

COX-2 (Accession number: S67722);

Forward: 5'-TGATGACTGCCCAACTCCCATG-3'

Reverse: 5'-AATGTTGAAGGTGTCCGGCAGC-3'

p53 (Accession number: NM_030989);

Forward: 5'-GTC GGC TCC GAC TAT ACC ACT ATC-3'

Reverse: 5'-CTC TCT TTG CAC TCC CTG GGG-3'

B-actin (Accession number: NM_031144.3);

Forward: 5'-TGTGATGGTGGGAATGGGTCAG-3'

Reverse: 5'-TTTGATGTCACGCACGATTTCC-3'.

The annealing temperature and time were optimized for each primer/template combination.

The amplified RT-PCR products $(10 \mu \mathrm{L})$ were mixed with $2 \mu \mathrm{L}$ of sample loading dye, electrophoresed on $1.5 \%$ agarose gel $(1.5 \mathrm{~g} / 100 \mathrm{~mL} 0.5 \mathrm{x}$ TBE) containing $10 \mu \mathrm{g} / \mathrm{mL}$ ethidium bromide (EtBr) dye, and visualized with gel documentation system. The intensity of bands was calculated by using UVI band max software program. The relative expression of TNF- $a, C O X-2$ and p53 transcripts were quantified and normalized to that of $\beta$-actin.

\section{Statistical analysis}

Statistical Package for the Social Sciences software (SPSS, version 16.0) was used for statistical analysis. Data were expressed as mean \pm standard error of the mean. Differences among groups were determined using one-way analysis of variance (ANOVA). Means were then statistically compared using Least Significant Difference (LSD) test. $P<0.05$ was considered to indicate a statistically significant difference.

\section{Results}




\section{Effect of BPA and/or GSPE on antioxidant and oxidative stress status of rat's brains}

BPA-treated rats showed a significant increase $(P<0.05)$ in MDA and Nitric oxide levels in brain compared to control group. While, levels of GSH and total thiol and the activities of the antioxidant enzymes GPx, SOD and GST in the rat brain were found to be significantly increased $(P<0.05)$ in BPA-treatment group as compared to control group. Pre-treatment of rats in (GSPE + BPA)-group with GSPE attenuate the oxidative stress and improve the antioxidant status as observed by the significant reduction $(P<0.05)$ in MDA and NO levels and significant increase $(P<0.05)$ in GSH, total thiol, GPx, SOD and GST in brain of rats as compared to BPA-group. The treatment with GSPE alone return all of the above parameters back to the levels of control or improve the antioxidant status over the control values (Tables 1 and 2).

\section{Table (1)}

Changes in the levels of oxidative stress and non-enzymatic antioxidant parameters and total protein content in brain extract of different experimental groups.

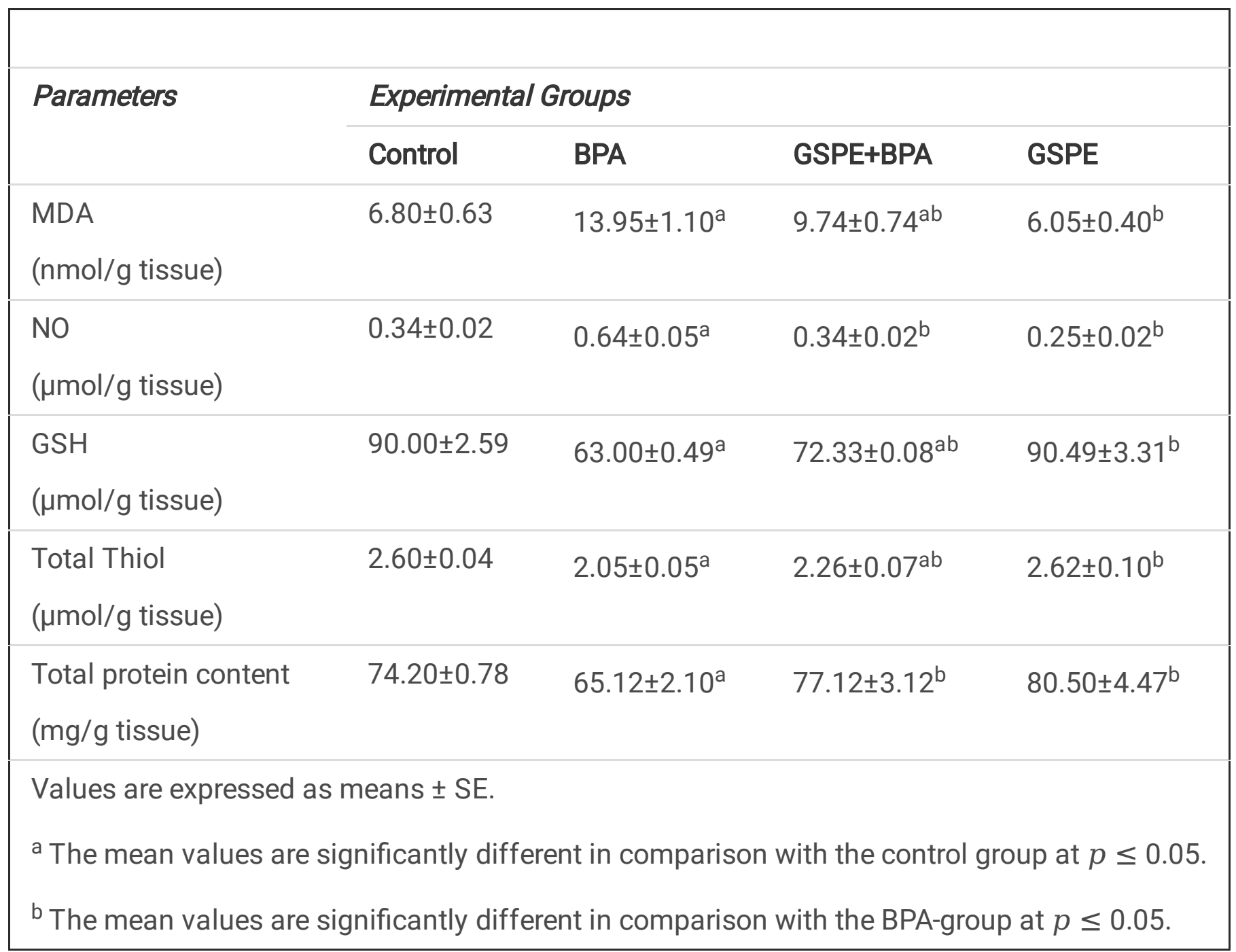


Table (2)

Changes in the levels of enzymatic antioxidants and detoxificants activities in brain extract of different experimental groups.

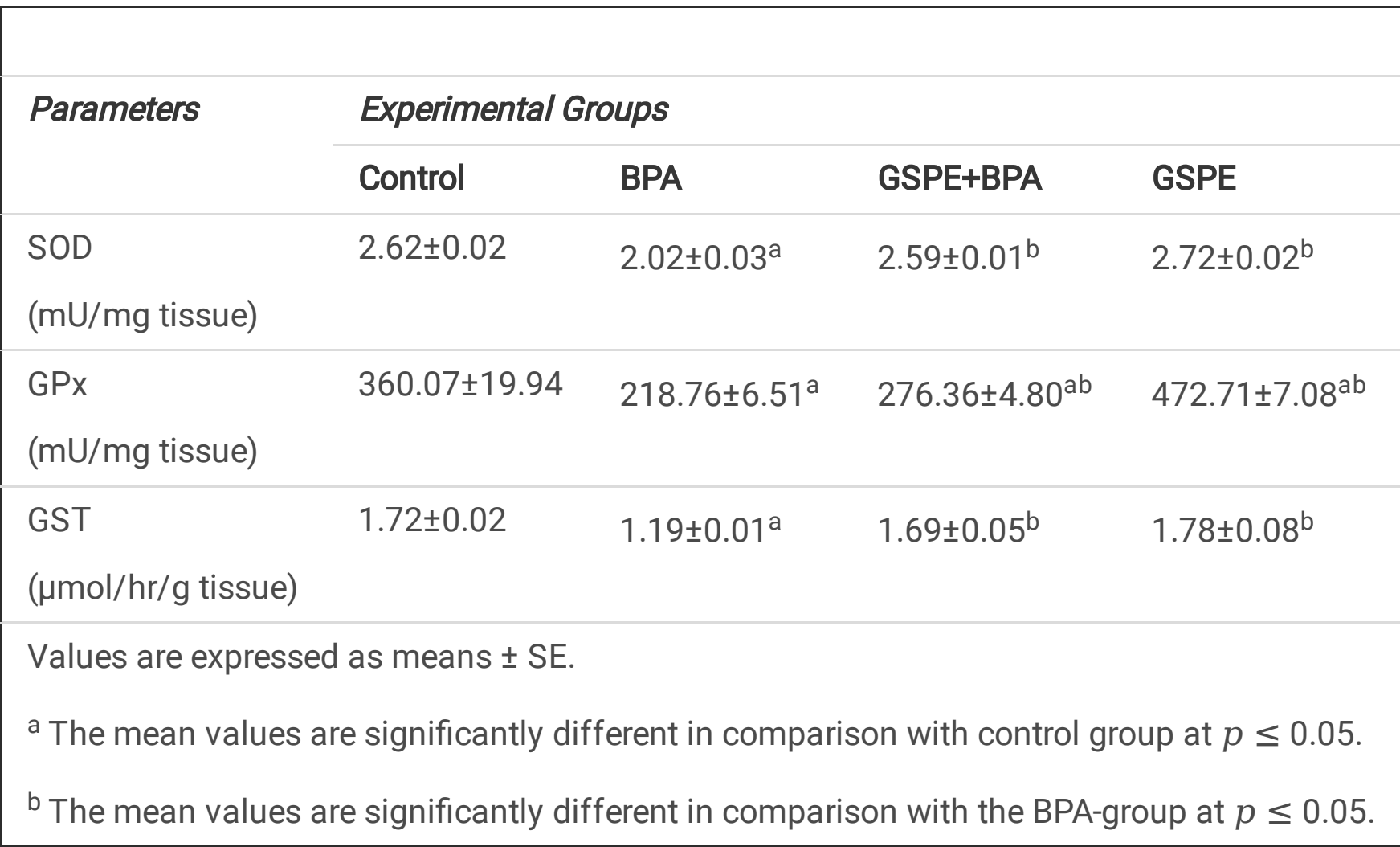

\section{Effect of BPA and/or GSPE on serum lipid profile}

Data represented in table 3 showed values of TC, TG, LDL-C and HDL-C in the serum of different groups. BPA significantly $(P<0.05)$ increased serum levels of $T C, T G$ and LDL-C in BPA-group compared to control. However, HDL-C level was significantly decreased $(P<0.05)$. Oral ingestion of GSPE before BPA improved the serum lipid profile as indicated by significant reduction $(P<0.05)$ in serum levels of TC, TG and LDL-C and significant increase $(P<0.05)$ in serum HDL-C as compared to BPA-group. Also, ingestion of GSPE alone in the last group significantly $(P<0.05)$ improve serum lipid profile compared to both control and BPA-groups.

Table (3)

Changes in the levels of serum lipids profile in different experimental groups. 


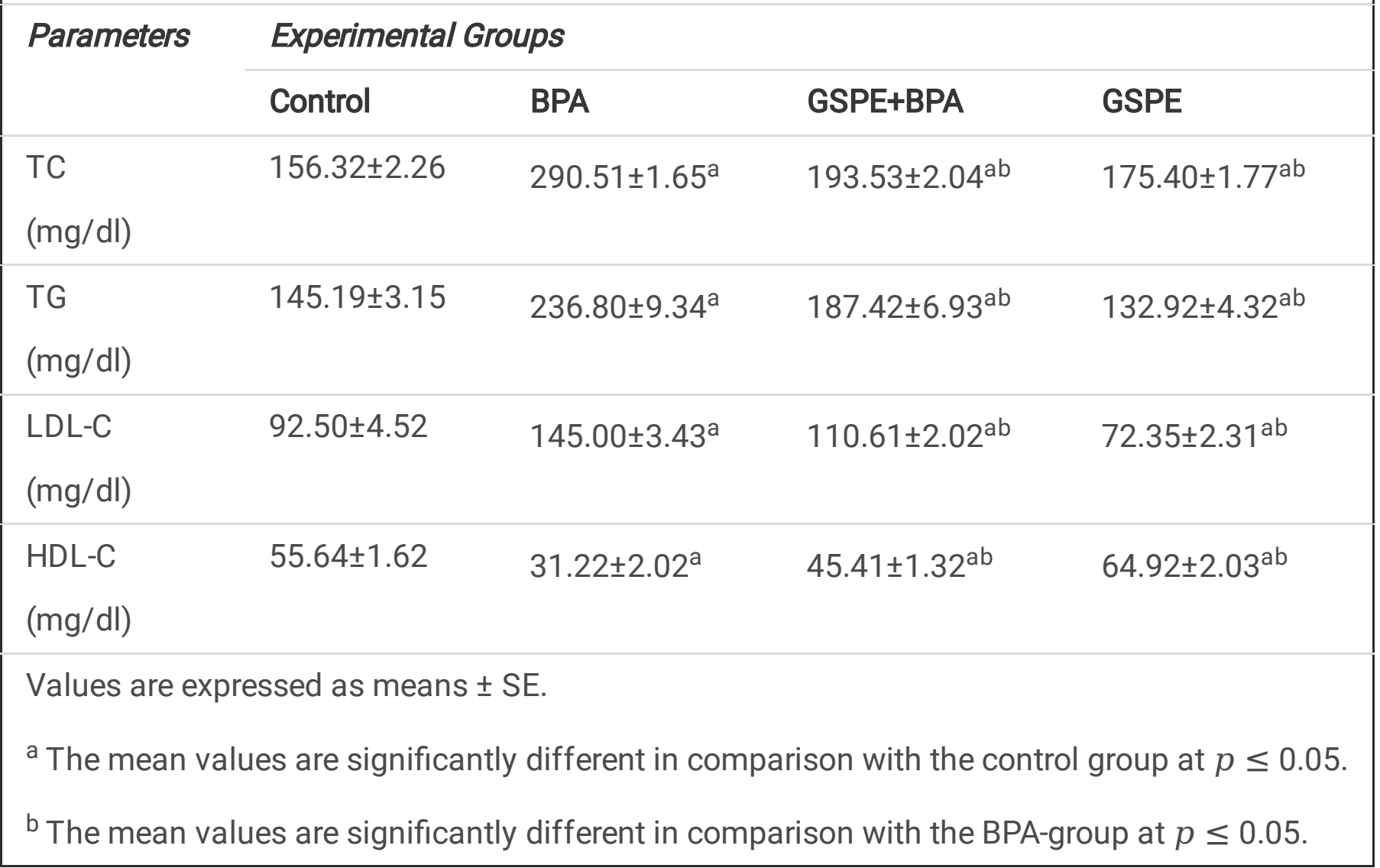

\section{Effect of BPA and/or GSPE on the activities of AchE, Na/K- ATPase and total ATPase in rat's brains}

One-way ANOVA followed by (LSD) test revealed a significant increase $(P<0.05)$ in the specific activity of AchE in BPA-treated group as compared to control. However, significant reduction $(P<0.05)$ was observed in the specific activities of $\mathrm{Na} / \mathrm{K}$-ATPase and total ATPase in the same group compared to control. Oral ingestion of GSPE alone or before BPA exposure significantly decreased $(P<0.05)$ the activity of AchE and significantly increased $(P<0.05)$ the activities of $\mathrm{Na} / \mathrm{K}$-ATPase and total ATPase in brain compared to BPA-treated group (Table 4).

\section{Table (4)}

Changes in the activities of AchE, $\mathrm{Na} / \mathrm{K}-\mathrm{ATP}$ ase and total ATPase in brain extract of different experimental groups. 


\begin{tabular}{|c|c|c|c|c|}
\hline \multirow[t]{2}{*}{ Parameters } & \multicolumn{4}{|c|}{ Experimental Groups } \\
\hline & Control & BPA & GSPE+BPA & GSPE \\
\hline $\begin{array}{l}\text { AchE } \\
\text { (nmol/min/mg protein) }\end{array}$ & $87.15 \pm 1.33$ & $101.65 \pm 4.07^{a}$ & $90.89 \pm 2.30^{b}$ & $81.18 \pm 3.88^{b}$ \\
\hline $\begin{array}{l}\mathrm{Na} / \mathrm{K}-\mathrm{ATP} \text { ase } \\
(\mu \mathrm{mol} / \mathrm{min} / \mathrm{mg} \text { protein) }\end{array}$ & $3.81 \pm 0.12$ & $1.52 \pm 0.02^{\mathrm{a}}$ & $2.79 \pm 0.02^{\mathrm{ab}}$ & $4.40 \pm 0.08^{\mathrm{ab}}$ \\
\hline $\begin{array}{l}\text { Total ATPase } \\
(\mu \mathrm{mol} / \mathrm{min} / \mathrm{mg} \text { protein })\end{array}$ & $2.01 \pm 0.02$ & $1.20 \pm 0.02^{\mathrm{a}}$ & $1.79 \pm 0.01^{\mathrm{ab}}$ & $2.80 \pm 0.02^{\mathrm{ab}}$ \\
\hline $\begin{array}{l}\text { Values are expressed as } \\
{ }^{a} \text { The mean values are si } \\
{ }^{b} \text { The mean values are si }\end{array}$ & $\begin{array}{l}\text { ans } \pm \text { SE. } \\
\text { ficantly differ } \\
\text { ficantly differ }\end{array}$ & $\begin{array}{l}\text { in comparison } \\
\text { in comparison }\end{array}$ & $\begin{array}{l}\text { th the control } \mathrm{c} \\
\text { th the BPA-gro }\end{array}$ & $\begin{array}{l}\text { up at } p \leq 0.05 \text {. } \\
\text { at } p \leq 0.05\end{array}$ \\
\hline
\end{tabular}

\section{Effect of BPA and/or GSPE on dopamine and serotonin levels in rat's brains}

The data represented in Figs. 1 and 2 summarized the levels of dopamine and serotonin in the brain of experimentally studied animals. The results indicated that the brain levels of dopamine and serotonin were significantly increased $(P<0.05)$ in rats treated with BPA compared to control. On the contrary, treatment with GSPE before BPA in (GSPE + BPA)-treated group significantly decreased $(P<0.05)$ levels of dopamine and serotonin in the brain compared to BPA-group. Non-significant differences were observed in the levels of dopamine and serotonin in brains of GSPE-group compared with that of control group.

\section{Effect of BPA and/or GSPE on gene expression levels of TNF-a, COX-2 and p53 in rat's brains}

Effect of chronic exposure to BPA alone or after ingestion of GSPE on gene expression of TNF-a, COX-2 and p53 in brain cells of different treated group was measured relative to $\beta$-actin and represented in Figs. 3-6. Results indicated that treatment with BPA significantly induced $(P<0.05)$ expression of TNF-a, COX-2 and p53 genes (lane 2) in brain as compared to that of control group (lane 1). Oral ingestion of GSPE alone (GSPE-group) or before BPA ingestion (GSPE + BPA-group) caused significant repression ( $\mathrm{P}<$ 0.05 ) in TNF-a, COX-2 and p53 mRNA expressions in brain (lanes 3 and 4) as compared to BPA-treated group (lane 2). The mRNA expressions of TNF-a, COX-2 and p53 were barely detectable in GSPE + BPA and GSPE-treated groups and were non-significantly different from that of control group. 


\section{Discussion}

\section{Neurotoxic effects of bisphenol A}

The brain is highly susceptible to oxidative damage because it uses high amounts of oxygen, has high quantities of polyunsaturated fatty acids and has relatively low antioxidant defence system ( $\mathrm{Li}$ et al. 2013). The present study revealed that BPA induced oxidative stress in brain tissues of rats as indicated by increased nitric oxide and MDA, reduction of glutathione and total thiol levels and inhibition of antioxidant enzymes; GPx, SOD and GST compared to control group. Thus, at the current dose of BPA, the antioxidant system of brain was unable to provide complete protection against the induced free radical damage. These results are in line with other study reported that BPA can increase levels of MDA and ROS, and reduce antioxidant defence system such as glutathione, catalase, and SOD (Hassani et al. 2017). The decreased activities of SOD and GPx in our study reflected the increased ROS and lipid peroxidation levels. BPA converted into reactive species by phase I enzymes system. The reduction in GST activity leads to non-neutralization of these reactive species and contribute to oxidative stress at the brain (Chahine \&O'Donnell 2011). It has been reported that BPA accumulated in mitochondrial membrane and lead to inhibition of complex I of the respiratory chain, interference with electron transport and produce more ROS (Khan et al. 2016). The decreased brain GSH level in this study could be due to consumption of GSH in large amount to combat BPA- induced free radical damage. The elevated LPO contents in the brain tissues of BPA exposed rats in the present study could lead to acute damage of the brain cells. NO, at high concentration, and its metabolite ONOO and ROS are key mechanisms in both necrotic and apoptotic cell death which may implicated in destruction of neuronal cells, severe inflammatory disorders and neurodegenerative diseases (Paul et al. 2018).

The chronic exposure to BPA in this study induced dyslipidimic state in the blood of experimental rats. This dyslipidimic state was confirmed by increased levels of serum TC, TG and LDL-C accompanied to decreased level of serum HDL-C. The current results are matched with that of Eweda et al. (2020) who reported that oral ingestion of $30 \mathrm{mg} \mathrm{BPA} / \mathrm{kg} \mathrm{BW}$ daily for 6 weeks induced disruption in serum lipid profile associated with accumulation of TG and cholesterol in liver tissues of rats (Eweda et al. 2020). It has been demonstrated that BPA disrupts the neuroendocrine mechanisms that regulate food intake and energy expenditure which chronically may leads to obesity and dyslipidmic state (Stoker et al. 2020). BPA-induced hypercholesterolemia could increase the overproduction of ROS by increasing mitochondrial respiration and decreasing the efficiency of antioxidant system (Thiruchenduran et al. 2011).

Alterations in the neurotoxicity biomarkers as AChE, $\mathrm{Na}^{+} / \mathrm{K}^{+}$-ATPase, dopamine and serotonin have been used to measure the neurotoxicity of environmental chemicals (Wu \&Li 2015). AChE is a robust and reliable diagnostic and prognostic markers of neurotoxicity and neuro-inflammation (Anand \&Singh 2013). Our results revealed an increase in the activity of AchE in BPA-treated group compared to control. The increased activity of AChE may suggest the neurotoxic effect of BPA at the dose administered. On the other hand, the chronic exposure to high dose of BPA reduced the activities of total and $\mathrm{Na}^{+} / \mathrm{K}^{+}-$ ATPase in the brain cells of the same group. The reduction in $\mathrm{N}^{+} / \mathrm{K}^{+}$-ATPase activity alters neuronal 
excitability and negatively affect sodium-calcium exchangers resulting in intracellular acidification, calcium overload and neuronal damage (Shrivastava et al. 2020). Also, the decreased activity of total and $\mathrm{Na}^{+} / \mathrm{K}^{+}$-ATPase in brain may be attributed to the oxidative stress induced by the chronic exposure to BPA as illustrated in this study.

Our results revealed that treatment with BPA resulted in elevated dopamine and serotonin levels in brain. These results are in consistence with a study reported that subcutaneous administration of BPA increased dopamine levels in brain tissue of pregnant mice ((Michałowicz 2014). Also, significant effects were observed in the levels of dopamine and serotonin in rat offspring orally administered BPA at high concentrations (Honma et al. 2006). The increased dopamine and serotonin concentrations may result from effects of BPA on dopamine re-uptake, monoamine oxidase (MAO) and serotonin release. The elevated dopamine may be subjected to metabolism by monoamine oxidase or autoxidized generating toxic products such as hydrogen peroxide, oxygen-derived radicals, semiquinones, and quinones which may exert neurotoxic effects (Ben-Shachar et al. 1995). Also, the reduction of serotonin metabolites after administration of BPA suggesting a reduction in the activity of metabolic enzymes, such as MAO, and subsequent elevation of serotonin in the brain (Negishi et al. 2004).

Damaged or diseased brain cells express and release high levels of the pro-inflammatory cytokine, TNF-a (Montgomery \&Bowers 2012). Also, COX-2 enzymes actively participate in inflammation reactions and associated in pathological mechanisms of aging and neurodegeneration (Lacy et al. 2016). Moreover, under stress or pathological conditions, p53 activate pro-oxidant genes, repress antioxidant genes and promoting more severe pro-oxidant state (Chatoo et al. 2011). At the molecular level, our study revealed that the chronic exposure to BPA increased gene expression levels of TNF-a, COX-2 and p53 in brain. These findings are in accordance with other results revealed that the sub-chronic exposure to BPA significantly increased gene expression of pro-inflammatory cytokine TNF-a, IL-17, and IL-6 in male mice which indicate on the neuroinflammation and neurotoxicity (Khan et al. 2019). Also, it has been shown that BPA exposure induces the expression of COX-2 and exacerbates inflammation (Song et al. 2017). The over production of ROS and RNS, as in the present study, can induce p53 expression and production of high pro-inflammatory cytokines such as IL- 6 and TNF-a (Solleiro-Villavicencio \&Rivas-Arancibia 2018). Moreover, it has been reported that TNF-a rapidly stimulate over production of damaging free radicals via upregulation of COX-2 which may contribute in necrotic neuronal cell death (Phillis et al. 2006). In addition, when the anti-oxidative capacity is greatly surpassed, p53 exhibits pro-oxidative activity that ends in cell death (Liu \&Xu 2011). All these events ultimately contribute to widespread neuronal death and the possibility of neurodegeneration disorders.

\section{Protective effect of grape seeds proanthocyanidins against BPA-neurotoxicity}

Natural products containing flavonoids, tannins and polyphenols (as Proanthocyanidins) have the ability to protect against oxidative stress and could represent important tool for decreasing the progression of 
neurodegenerative diseases in animal and humans (Davinelli et al. 2016). The current study revealed the neuroprotective effects of GSPE against BPA-induced brain toxicity. Treatment of rats with GSPE before exposure to BPA resulted in significant reduction in the brain oxidative stress as indicated by reduction of MDA and NO to a levels comparable to that of control. Also, GSPE increased the levels of GSH and total thiol contents and the activities of SOD, GPx and GST in brain cells compared to control group. Previous study showed that grape seed extract had a protective effect on brain by decreasing levels of MDA, scavenging of ROS and upregulating of antioxidant enzymes (Jiao et al. 2017). The anti-oxidative mechanisms of GSPE include radical scavenging action, singlet oxygen quenching action and chelating action. GSPE played a role in decreasing the iron levels, which participate in Fenton reaction, through their iron chelation with their o-diphenol groups (Yun et al. 2020). The increased GSH content after administration of GSPE may be attributed to enhancement of its synthesis via increasing the expression of $\mathrm{Y}$-glutamyl-cysteine synthetase (Bagchi et al. 2002). The decreased NO level may be result from reduced gene expression of iNOS mRNA by GSPE (Harbeoui et al. 2019). Also, the ability of GSPE to restore the normal levels of vitamin $E$ and $C$ could account for the reduction of free radical and oxidative stress in the brain of BPA-treated rats (Balu et al. 2006).

The pre-treatment of BPA group with GSPE attenuate the dyslipidemic state in these rats through reduction of serum TC, TG and LDL-C associated with elevation of HDL-C. These results are in line with other research revealed that oral administration of GSPE for two months ameliorate the levels of total lipids, TC, TG, LDL-C and HDL-C in gibberellic acid-treated male rats (Hassan \&Al-Rawi 2013). GSPE was reported to develop lipid homeostasis by enhancing cholesterol removal in bile, decreased plasma TG and LDL-C levels and increased plasma HDL-C (Del Bas et al. 2005). GSPE-rich foods also inhibit digestive enzymes and suppress fat and glucose absorption from the gut via inhibition of lipase and amylase (Salvadó et al. 2015). The feeding of HFD-rats with grape seed flour augmented fatty acid oxidation, increased lipolysis and decreased fatty acid synthesis in these rats which could explain the attenuation of dyslipidemic state induced by BPA (Zhou et al. 2019).

The neuroprotective effects of GSPE in the current study were observed in the restoration of the activities of AchE, $\mathrm{Na}$ /K-ATPase and total ATPase in brain tissue to levels comparable with the control group. Our results were in consistent with other study showed that the oral ingestion of GSPE increased the concentration of acetylcholine with a moderate reduction in the activity of AchE in adult rats and minimizing age-related loss of cognition in older rats (Devi et al. 2006). The inhibition of AchE activity has been described to boost brain cholinergic function and amend memory deficit associated with neurodegenerative diseases (Adefeghaa et al. 2015). Also, $\mathrm{Na}^{+} / \mathrm{K}^{+}$-ATPase was suggested as a target for natural compounds, such as GSPE (Almaliti et al. 2013). It has been reported that the neuroprotective role of curcumin was attributed to the elevation in Na/K-ATPase activity in regions of rats' brain (Vajragupta et al. 2003). GSPE may attenuate or reduced neurotoxicity by its ability to increase $\mathrm{Na}^{+} / \mathrm{K}^{+}$-ATPase activity. On the other hand, the reduction in dopamine and serotonin levels were observed in the brain of GSPE+BPA and GSPE-groups. The decreased levels of dopamine and serotonin may be resulted from 
counteraction of GSPE to BPA-induced inhibition of MAO and to the reduction in neurotransmitter reuptake.

The pre-treatment of BPA-group with GSPE downregulate the gene expression of TNF-a, COX-2 and p53. Our results are consistence with previous study reported that GSPE suppress gene expression of TNF-a and COX-2 (Chu et al. 2016). The anti-inflammatory effect of GSPE could attributed to upregulation of peroxisome proliferator-activated receptor-y (PPAR- - ) expression and subsequent downregulation of COX2 expression (Liu et al. 2020). The decreased BPA-induced neuroinflammation by GSPE may be due to reduction of NO level via down-regulation of iNOS expression (Zhou et al. 2011). Also, p53 depletion attenuate neuronal death and protect neurons against apoptotic stimuli via decreased p53 DNA-binding activity, inhibition of caspases and prevention of mitochondrial dysfunction (Jembrek et al. 2018). Thus, the administration of GSPE might represent a promising approach for treatment of neuroinflammation, neurotoxicity and several neurodegenerative conditions.

\section{Conclusion}

Our research revealed that the chronic exposure to BPA was associated with brain oxidative stress, neuroinflammation and injury in neural tissue which may lead to degenerative diseases. The BPA-induced neuronal oxidative stress leads to alteration in neuro-specific enzymes; AchE, Na/K-ATPase and total ATPase and in neurotransmitters; dopamine and serotonin. These neuronal changes result in neuroinflammation, neurotoxicity and might neuronal death as indicated by overexpression of TNF-a, COX-2 enzyme and p53 protein. Also, the study demonstrated the protective effects of GSPE against the above mentioned BPA-induced neurotoxicity as indicated by the attenuation or amelioration of all oxidative and neurotoxic parameters induced by BPA. Our observations add to the body of evidence that GSPE may be a novel therapeutic agent for treating neurodegenerative disorders.

\section{Declarations}

\section{Author contributions}

Heba Mohamed Abdou and Heba-Tallah Abd Elkader conceived, designed the study and collect the data. Heba Mohamed Abdou, Heba-Tallah Abd Elkader, Saber M. Eweda and Amel H. El-Gendy Performed the experiments, analyzed the data, prepared figures and/or tables. Saber M. Eweda wrote the manuscript. All authors read, authored and approved the final manuscript submitted for publication.

\section{Funding}

This research did not receive any specific grant from funding agencies in the public, commercial, or notfor-profit sectors. 


\section{Availability of data and materials}

All the data and material were available. The data of this article are included within the article and its additional files.

\section{Ethics approval and consent to participate}

All the experimental and animal handling procedures were performed according to the guidelines approved by Alexandria University Institutional Animal Care and Use Committee (ALEXU-IACUC), a member of the International Council for Laboratory Animal Science (ICLAS) (Approval number: AU04200125201).

\section{Consent for publication}

All co-authors agree to publish this manuscript in the Journal (Environmental pollution and research)

\section{Conflict of Interest}

The authors declare that they have no conflicts of interest.

\section{References}

1. Adefeghaa S, Oboha G, Odubanjoa T, Ogunsuyia O (2015) A comparative study on the antioxidative activities, anticholinesterase properties and essential oil composition of clove (Syzygium aromaticum) bud and Ethiopian pepper (Xylopia aethiopica). Riv. Ital. Sost. Gr 92: 257-268

2. Agarwal S, Yadav A, Tiwari SK, Seth B, Chauhan LKS, Khare P, Ray RS, Chaturvedi RK (2016) Dynamin-related protein 1 inhibition mitigates bisphenol A-mediated alterations in mitochondrial dynamics and neural stem cell proliferation and differentiation. Journal of Biological Chemistry 291: 15923-15939

3. Almaliti J, Nada SE, Carter B, Shah ZA, Tillekeratne LV (2013) Natural products inspired synthesis of neuroprotective agents against $\mathrm{H} 2 \mathrm{O} 2$-induced cell death. Bioorganic \& medicinal chemistry letters 23: $1232-1237$

4. Anand P, Singh B (2013) A review on cholinesterase inhibitors for Alzheimer's disease. Archives of pharmacal research 36: 375-399

5. Bagchi D, Bagchi M, Stohs SJ, Ray SD, Sen CK, Preuss HG (2002) Cellular protection with proanthocyanidins derived from grape seeds. Annals of the New York Academy of Sciences 957: 260-270 
6. Balu M, Sangeetha P, Murali G, Panneerselvam C (2006) Modulatory role of grape seed extract on age-related oxidative DNA damage in central nervous system of rats. Brain research bulletin 68: 469473

7. Ben-Shachar D, Zuk R, Glinka Y (1995) Dopamine neurotoxicity: inhibition of mitochondrial respiration. Journal of neurochemistry $64: 718-723$

8. Braun JM, Muckle G, Arbuckle T, Bouchard MF, Fraser WD, Ouellet E, Séguin JR, Oulhote Y, Webster GM, Lanphear BP (2017) Associations of prenatal urinary bisphenol A concentrations with child behaviors and cognitive abilities. Environmental health perspectives 125: 067008

9. Chahine S, O'Donnell MJ (2011) Interactions between detoxification mechanisms and excretion in Malpighian tubules of Drosophila melanogaster. Journal of Experimental Biology 214: 462-468

10. Chatoo W, Abdouh M, Bernier G (2011) p53 pro-oxidant activity in the central nervous system: implication in aging and neurodegenerative diseases. Antioxidants \& redox signaling 15: 1729-1737

11. Chomczynski P, Sacchi N (2006) The single-step method of RNA isolation by acid guanidinium thiocyanate-phenol-chloroform extraction: twenty-something years on. Nature protocols 1: 581-585

12. Chu H, Tang Q, Huang H, Hao W, Wei X (2016) Grape-seed proanthocyanidins inhibit the lipopolysaccharide-induced inflammatory mediator expression in RAW264. 7 macrophages by suppressing MAPK and NF-kb signal pathways. Environmental toxicology and pharmacology 41: 159-166

13. Chu KO, Chan S-O, Pang CP, Wang CC (2014) Pro-oxidative and antioxidative controls and signaling modification of polyphenolic phytochemicals: contribution to health promotion and disease prevention? Journal of agricultural and food chemistry 62: 4026-4038

14. Davinelli S, Maes M, Corbi G, Zarrelli A, Willcox DC, Scapagnini G (2016) Dietary phytochemicals and neuro-inflammaging: from mechanistic insights to translational challenges. Immunity \& Ageing 13: 16

15. Del Bas JM, Fernández-Larrea J, Blay M, Ardèvol A, Salvadó MJ, Arola L, Bladé C (2005) Grape seed procyanidins improve atherosclerotic risk index and induce liver CYP7A1 and SHP expression in healthy rats. The FASEB journal 19: 1-24

16. Devi A, Jolitha AB, Ishii N (2006) Grape Seed Proanthocyanidin Extract (GSPE) and antioxidant defense in the brain of adult rats. Medical Science Monitor 12: BR124-BR129

17. Draper H, Hadley M (1990) [43] Malondialdehyde determination as index of lipid Peroxidation, Methods in enzymology. Elsevier, pp. 421-431

18. Ellman GL, Courtney KD, Andres Jr V, Featherstone RM (1961) A new and rapid colorimetric determination of acetylcholinesterase activity. Biochemical pharmacology 7: 88-95

19. Eweda SM, Newairy ASA, Abdou HM, Gaber AS (2020) Bisphenol A-induced oxidative damage in the hepatic and cardiac tissues of rats: The modulatory role of sesame lignans. Experimental and Therapeutic Medicine 19: 33-44

20. Flohe L, Günzler WA (1984) [12] Assays of glutathione peroxidase. Methods in enzymology 105: 114120 
21. Griffith OW (1980) Determination of glutathione and glutathione disulfide using glutathione reductase and 2-vinylpyridine. Analytical biochemistry 106: 207-212

22. Guevara I, Iwanejko J, Dembińska-Kieć A, Pankiewicz J, Wanat A, Anna P, Gołąbek I, Bartuś S, Malczewska-Malec M, Szczudlik A (1998) Determination of nitrite/nitrate in human biological material by the simple Griess reaction. Clinica Chimica Acta 274: 177-188

23. Habig WH, Pabst MJ, Jakoby WB (1974) Glutathione S-transferases the first enzymatic step in mercapturic acid formation. Journal of biological Chemistry 249: 7130-7139

24. Harbeoui H, Hichami A, Wannes WA, Lemput J, Tounsi MS, Khan N (2019) Anti-inflammatory effect of grape (Vitis vinifera L.) seed extract through the downregulation of NF-KB and MAPK pathways in LPS-induced RAW264. 7 macrophages. South African Journal of Botany 125: 1-8

25. Hassan HA, Al-Rawi MM (2013) Grape seeds proanthocyanidin extract as a hepatic-reno-protective agent against gibberellic acid induced oxidative stress and cellular alterations. Cytotechnology 65 : 567-576

26. Hassani FV, Mehri S, Abnous K, Birner-Gruenberger R, Hosseinzadeh H (2017) Protective effect of crocin on BPA-induced liver toxicity in rats through inhibition of oxidative stress and downregulation of MAPK and MAPKAP signaling pathway and miRNA-122 expression. Food and Chemical Toxicology 107: 395-405

27. Honma T, Miyagawa M, Suda M, Wang R-S, Kobayashi K, Sekiguchi S (2006) Effects of perinatal exposure to bisphenol A on brain neurotransmitters in female rat offspring. Industrial health 44: 510524

28. Jembrek MJ, Slade N, Hof PR, Šimić G (2018): The interactions of p53 with tau and Aß as potential therapeutic targets for Alzheimer's disease. Progress in neurobiology 168: 104-127

29. Jiao J, Wei Y, Chen J, Chen X, Zhang Y (2017): Anti-aging and redox state regulation effects of A-type proanthocyanidins-rich cranberry concentrate and its comparison with grape seed extract in mice. Journal of Functional Foods 30: 63-73

30. Khan J, Salhotra S, Goswami P, Akhter J, Jahan S, Gupta S, Sharma S, Banerjee BD, Parvez S, Gupta $S$ (2019): Bisphenol A triggers axonal injury and myelin degeneration with concomitant neurobehavioral toxicity in C57BL/6J male mice. Toxicology 428: 152299

31. Khan S, Beigh S, Chaudhari BP, Sharma S, Aliul Hasan Abdi S, Ahmad S, Ahmad F, Parvez S, Raisuddin S (2016) Mitochondrial dysfunction induced by Bisphenol A is a factor of its hepatotoxicity in rats. Environmental toxicology 31: 1922-1934

32. Lacy SH, Woeller CF, Thatcher TH, Maddipati KR, Honn KV, Sime PJ, Phipps RP (2016) Human lung fibroblasts produce proresolving peroxisome proliferator-activated receptor- $\gamma$ ligands in a cyclooxygenase-2-dependent manner. American Journal of Physiology-Lung Cellular and Molecular Physiology 311: L855-L867

33. Li J, Li W, Jiang Z-G, Ghanbari HA (2013) Oxidative stress and neurodegenerative disorders. International journal of molecular sciences 14: 24438-24475

34. Liu D, Xu Y (2011): p53, oxidative stress, and aging. Antioxidants \& redox signaling 15: 1669-1678 
35. Liu J, Hu S, Zhu B, Shao S, Yuan L (2020) Grape seed procyanidin suppresses inflammation in cigarette smoke-exposed pulmonary arterial hypertension rats by the PPAR- $\mathrm{Y} / \mathrm{COX}-2$ pathway. Nutrition, Metabolism and Cardiovascular Diseases 30: 347-354

36. Lowry OH, Rosebrough NJ, Farr AL, Randall RJ (1951) Protein measurement with the Folin phenol reagent. Journal of biological chemistry 193: 265-275

37. Marklund S, Marklund G (1974) Involvement of the superoxide anion radical in the autoxidation of pyrogallol and a convenient assay for superoxide dismutase. European journal of biochemistry 47 : 469-474

38. Michałowicz J (2014) Bisphenol A-sources, toxicity and biotransformation. Environmental toxicology and pharmacology 37: 738-758

39. Montgomery SL, Bowers WJ (2012) Tumor necrosis factor-alpha and the roles it plays in homeostatic and degenerative processes within the central nervous system. Journal of neuroimmune pharmacology 7: 42-59

40. Musachio EAS, Araujo SM, Bortolotto VC, de Freitas Couto S, Dahleh MMM, Poetini MR, Jardim EF, Meichtry LB, Ramborger BP, Roehrs R (2020) Bisphenol A exposure is involved in the development of Parkinson like disease in Drosophila melanogaster. Food and Chemical Toxicology 137: 111128

41. Nassiri-Asl M, Hosseinzadeh $\mathrm{H}$ (2009) Review of the pharmacological effects of Vitis vinifera (Grape) and its bioactive compounds. Phytotherapy Research: An International Journal Devoted to Pharmacological and Toxicological Evaluation of Natural Product Derivatives 23: 1197-1204

42. Negishi T, Kawasaki K, Suzaki S, Maeda H, Ishii Y, Kyuwa S, Kuroda Y, Yoshikawa Y (2004) Behavioral alterations in response to fear-provoking stimuli and tranylcypromine induced by perinatal exposure to bisphenol A and nonylphenol in male rats. Environmental health perspectives 112: 1159-1164

43. Niranjan R (2018) Recent advances in the mechanisms of neuroinflammation and their roles in neurodegeneration. Neurochemistry international 120: 13-20

44. Paul R, Phukan BC, Thenmozhi AJ, Manivasagam T, Bhattacharya P, Borah A (2018) Melatonin protects against behavioral deficits, dopamine loss and oxidative stress in homocysteine model of Parkinson's disease. Life sciences 192: 238-245

45. Phillis JW, Horrocks LA, Farooqui AA (2006) Cyclooxygenases, lipoxygenases, and epoxygenases in CNS: their role and involvement in neurological disorders. Brain research reviews 52: 201-243

46. Prasain JK, Peng N, Dai Y, Moore R, Arabshahi A, Wilson L, Barnes S, Wyss JM, Kim H, Watts RL (2009) Liquid chromatography tandem mass spectrometry identification of proanthocyanidins in rat plasma after oral administration of grape seed extract. Phytomedicine 16: 233-243

47. Raisuddin S, Sharma S (2017) Endocrine-disrupting chemicals in food and their toxicological implications, Food Toxicology. Apple Academic Press, pp. 199-250

48. Resnik DB, Elliott KC (2015) Bisphenol A and risk management ethics. Bioethics 29: 182-189

49. Salvadó MJ, Casanova E, Fernández-Iglesias A, Arola L, Bladé C (2015) Roles of proanthocyanidin rich extracts in obesity. Food \& function 6: 1053-1071 
50. Sedlak J, Lindsay RH (1968) Estimation of total, protein-bound, and nonprotein sulfhydryl groups in tissue with Ellman's reagent. Analytical biochemistry 25: 192-205

51. Shan $Y$, Ye X-h, Xin H (2010) Effect of the grape seed proanthocyanidin extract on the free radical and energy metabolism indicators during the movement. Scientific Research and Essays 5: 148-153

52. Shrivastava AN, Triller A, Melki R (2020) Cell biology and dynamics of Neuronal Na+/K+-ATPase in health and diseases. Neuropharmacology 169: 107461

53. Solleiro-Villavicencio H, Rivas-Arancibia S (2018) Effect of chronic oxidative stress on neuroinflammatory response mediated by CD4+ T cells in neurodegenerative diseases. Frontiers in cellular neuroscience 12: 114

54. Song H, Park J, Bui PT, Choi K, Gye MC, Hong Y-C, Kim JH, Lee YJ (2017) Bisphenol A induces COX-2 through the mitogen-activated protein kinase pathway and is associated with levels of inflammationrelated markers in elderly populations. Environmental research 158: 490-498

55. Stoker C, Andreoli MF, Kass L, Bosquiazzo VL, Rossetti MF, Canesini G, Luque EH, Ramos JG (2020) Perinatal exposure to bisphenol A (BPA) impairs neuroendocrine mechanisms regulating food intake and kisspetin system in adult male rats. Evidences of metabolic disruptor hypothesis. Molecular and cellular endocrinology 499: 110614

56. Sutcliffe TC, Winter AN, Punessen NC, Linseman DA (2017) Procyanidin B2 protects neurons from oxidative, nitrosative, and excitotoxic stress. Antioxidants 6: 77

57. Thiruchenduran M, Vijayan NA, Sawaminathan JK, Devaraj SN (2011) Protective effect of grape seed proanthocyanidins against cholesterol cholic acid diet-induced hypercholesterolemia in rats. Cardiovascular Pathology 20: 361-368

58. Tyl R, Myers C, Marr M, Thomas B, Keimowitz A, Brine D, Veselica M, Fail P, Chang T, Seely J (2002) Three-generation reproductive toxicity study of dietary bisphenol A in CD Sprague-Dawley rats. Toxicological Sciences 68: 121-146

59. Vajragupta O, Boonchoong P, Watanabe H, Tohda M, Kummasud N, Sumanont $Y$ (2003) Manganese complexes of curcumin and its derivatives: evaluation for the radical scavenging ability and neuroprotective activity. Free Radical Biology and Medicine 35: 1632-1644

60. Wu J-P, Li M-H (2015) Inhibitory effects of pain relief drugs on neurological enzymes: implications on their potential neurotoxicity to aquatic animals. Environmental toxicology and pharmacology 39 : 898-905

61. Yousef M, Saad A, El-Shennawy L (2009) Protective effect of grape seed proanthocyanidin extract against oxidative stress induced by cisplatin in rats. Food and Chemical Toxicology 47: 1176-1183

62. Yun S, Chu D, He X, Zhang W, Feng C (2020) Protective effects of grape seed proanthocyanidins against iron overload-induced renal oxidative damage in rats. Journal of Trace Elements in Medicine and Biology 57: 126407

63. Zhang S, Cui Y, Li L, Li Y, Zhou P, Luo L, Sun B (2015) Preparative HSCCC isolation of phloroglucinolysis products from grape seed polymeric proanthocyanidins as new powerful antioxidants. Food chemistry 188: 422-429 
64. Zhao J, Bi W, Xiao S, Lan X, Cheng X, Zhang J, Lu D, Wei W, Wang Y, Li H (2019) Neuroinflammation induced by lipopolysaccharide causes cognitive impairment in mice. Scientific reports 9: 1-12

65. Zhou D-y, Du Q, Li R-r, Huang M, Zhang Q, Wei G-z (2011) Grape seed proanthocyanidin extract attenuates airway inflammation and hyperresponsiveness in a murine model of asthma by downregulating inducible nitric oxide synthase. Planta medica 77: 1575-1581

66. Zhou F, Yin M, Liu Y, Han X, Guo J, Ren C, Wang W, Huang W, Zhan J, You Y (2019) Grape seed flour intake decreases adiposity gain in high-fat-diet induced obese mice by activating thermogenesis. Journal of Functional Foods 62: 103509

\section{Figures}

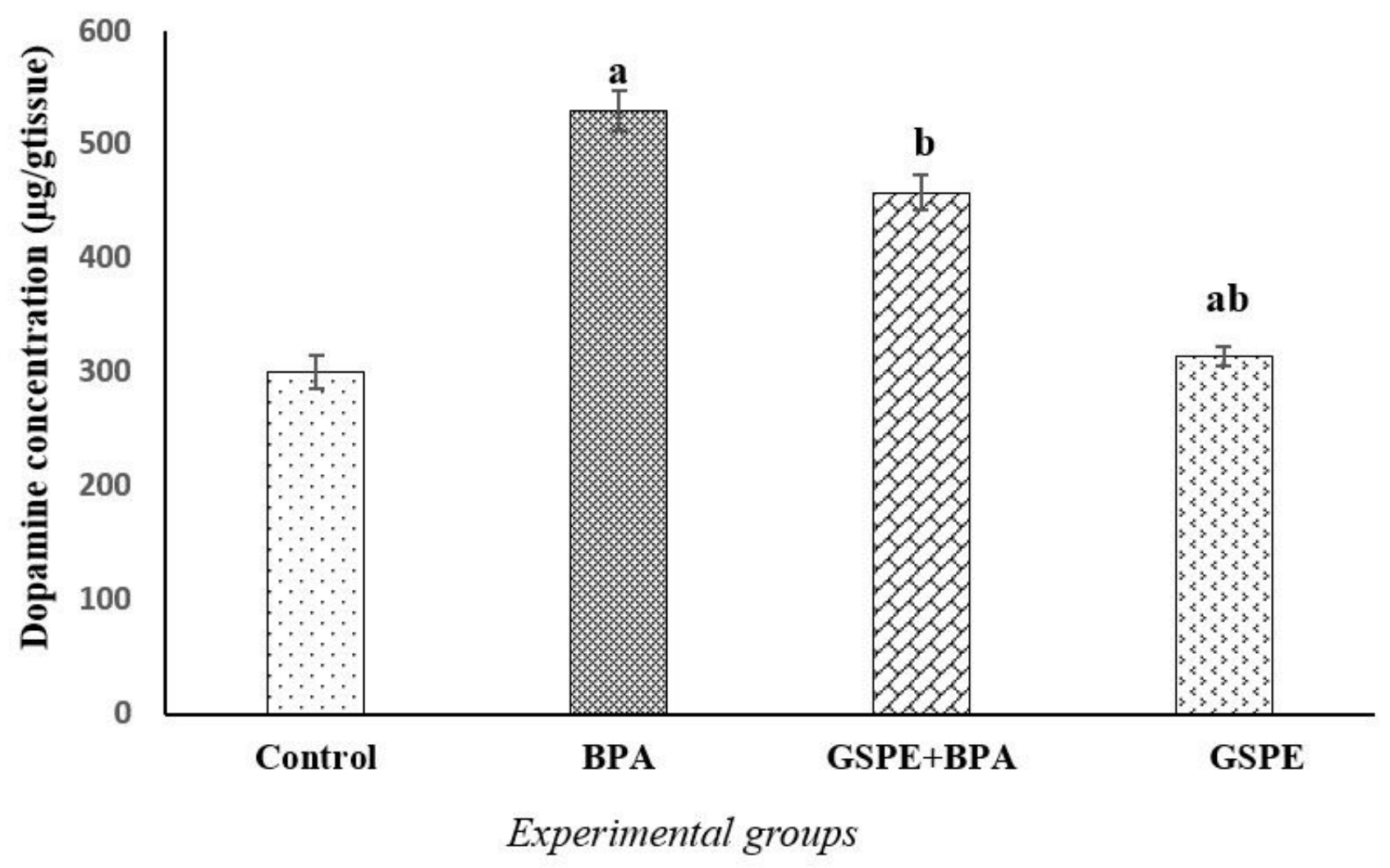

Figure 1

Effect of treatments on dopamine levels in brain tissues of rats in different experimental group. All the data were analyzed using one-way ANOVA followed by LSD test. Values are expressed as means of 7 rats \pm SE as compared to control group (a), BPA-treated group (b) at $P<0.05$. 


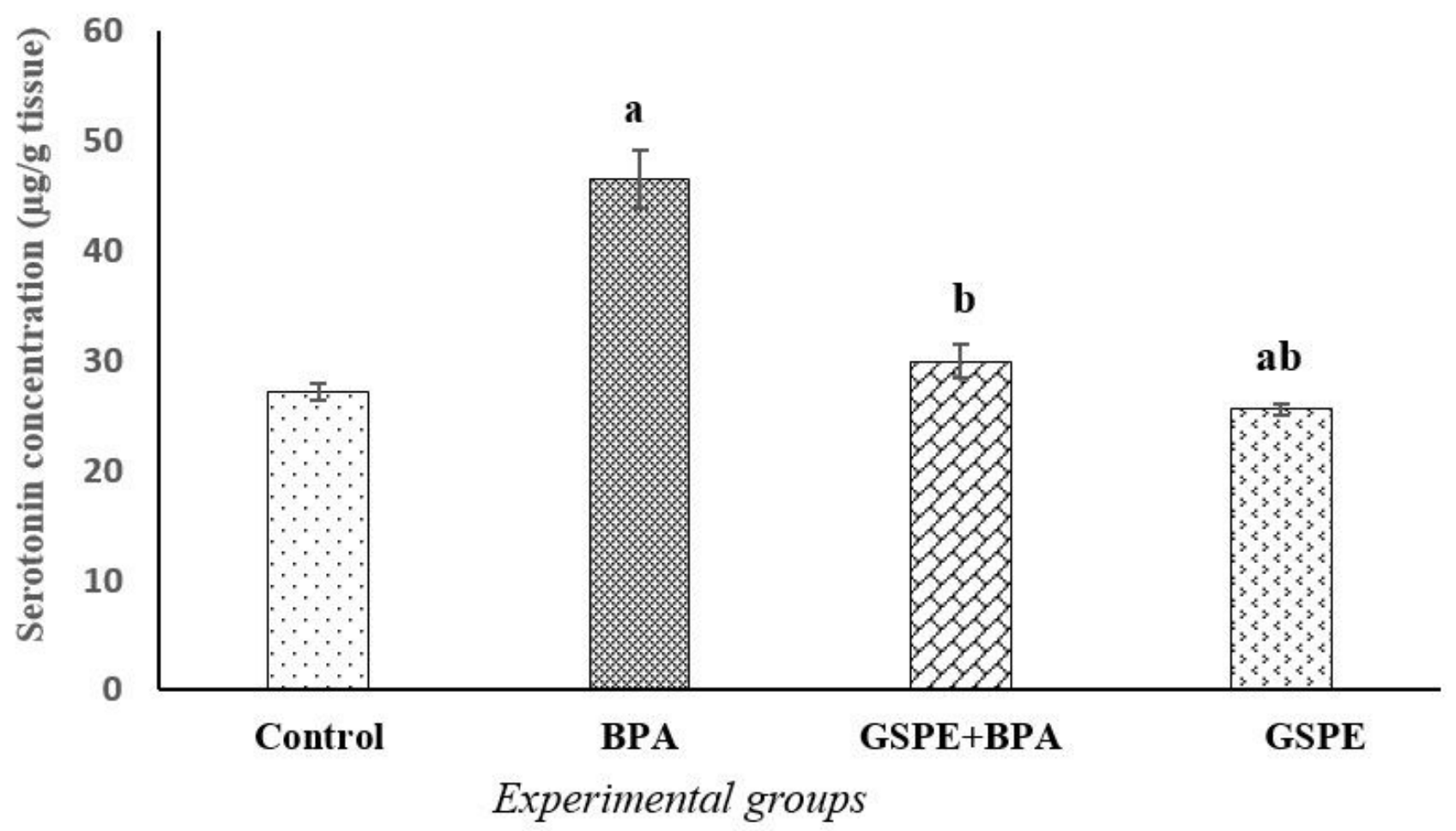

Figure 2

Effect of treatments on serotonin levels in brain tissues of rats in different experimental group. All the data were analyzed using one-way ANOVA followed by LSD test. Values are expressed as means of 7 rats \pm SE as compared to control group (a), BPA-treated group (b) at $\mathrm{P}<0.05$. 


\section{GSPE}

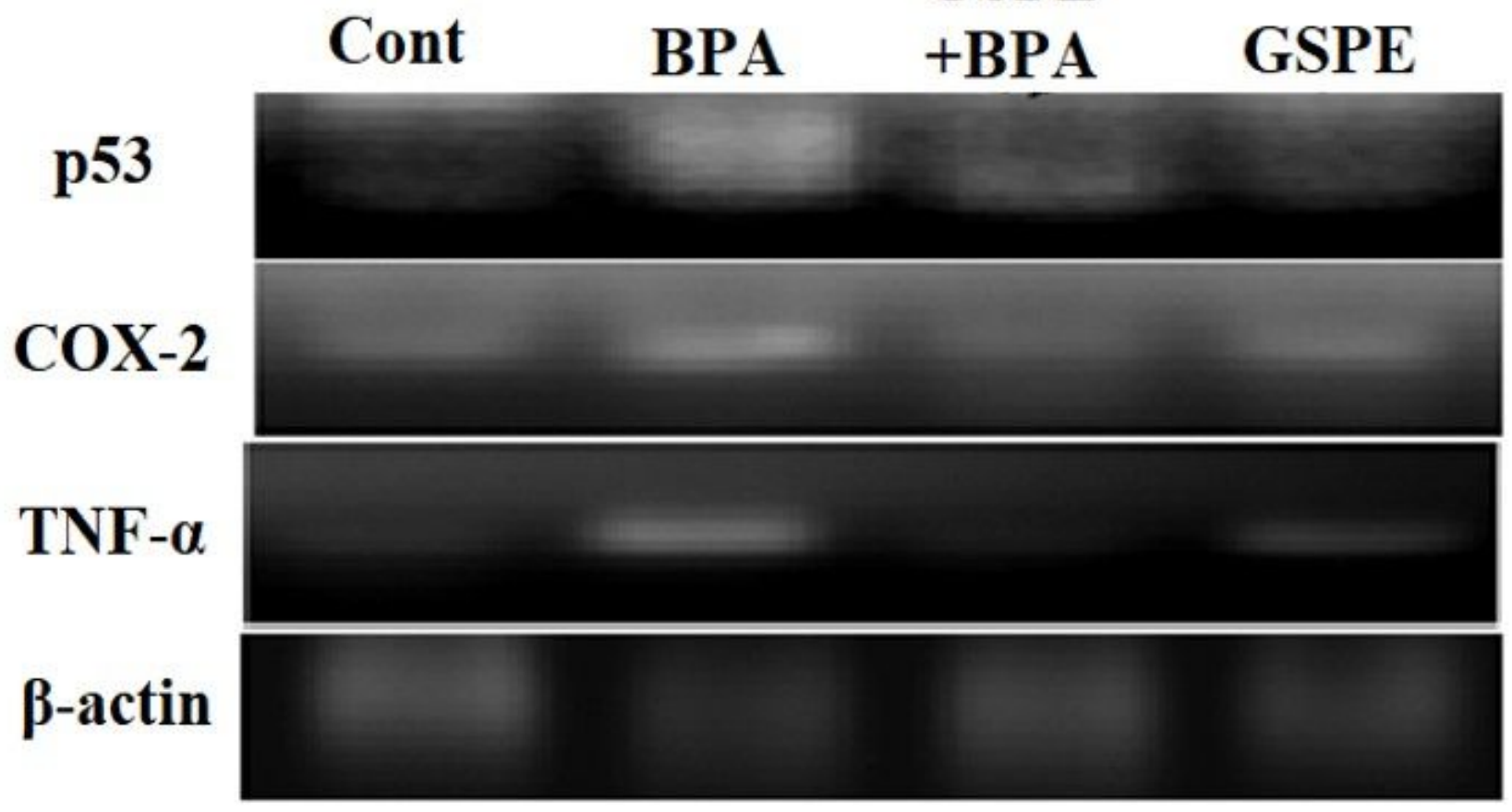

\section{Figure 3}

Effect of treatments on reverse-transcriptase PCR (RT-PCR) analysis of p53, COX-2 and TNF-a mRNA expression in brain tissues of rats in different experimental group. $\beta$-actin serves as the loading control. 


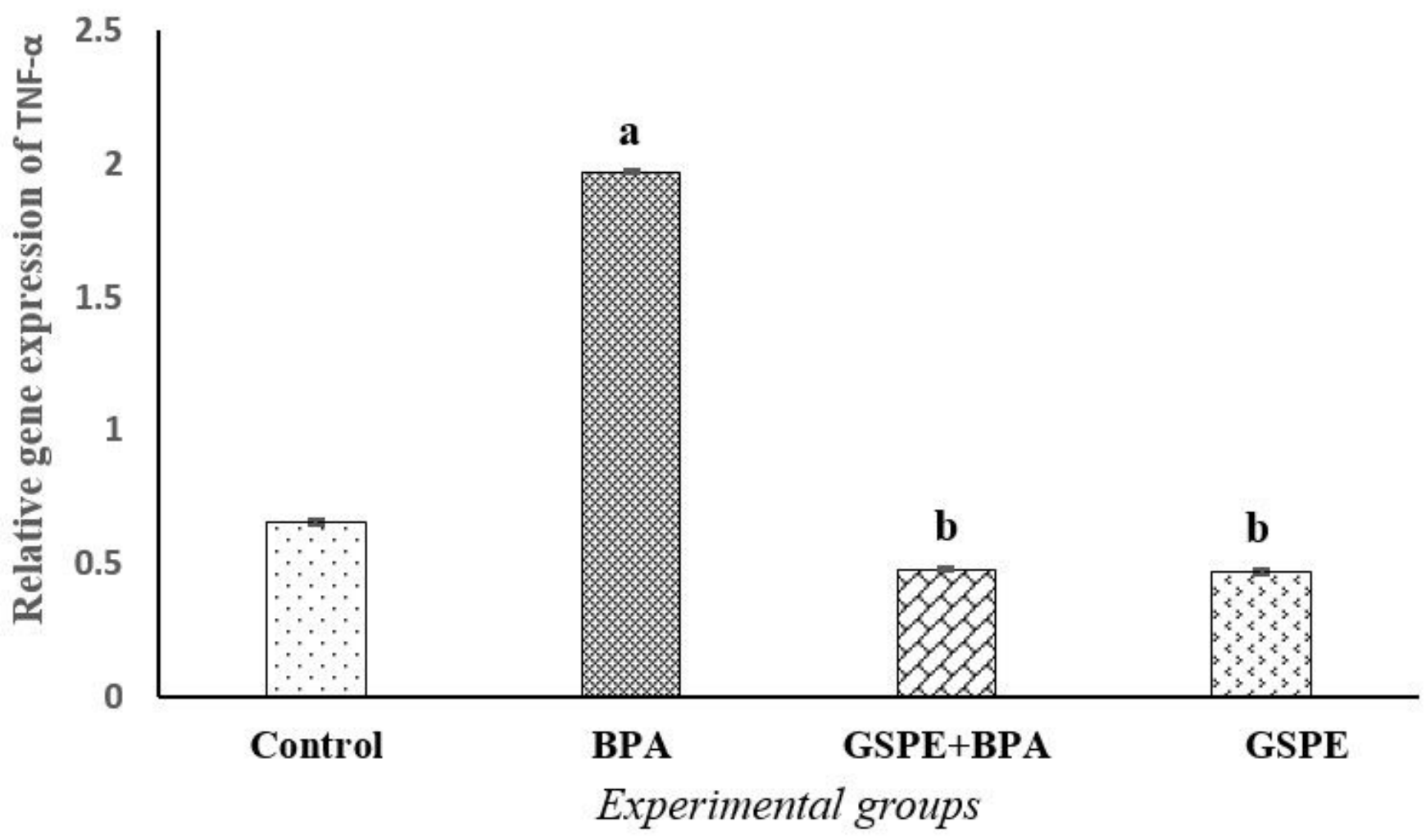

Figure 4

Effect of treatments on relative gene expression level of TNF- $a$ in brain tissues of rats in different experimental group. $\beta$-actin serves as internal control. All the data were analyzed using one-way ANOVA followed by LSD test. Values are expressed as means of 7 rats \pm SE as compared to control group (a), BPA-treated group (b) at $\mathrm{P}<0.05$. 


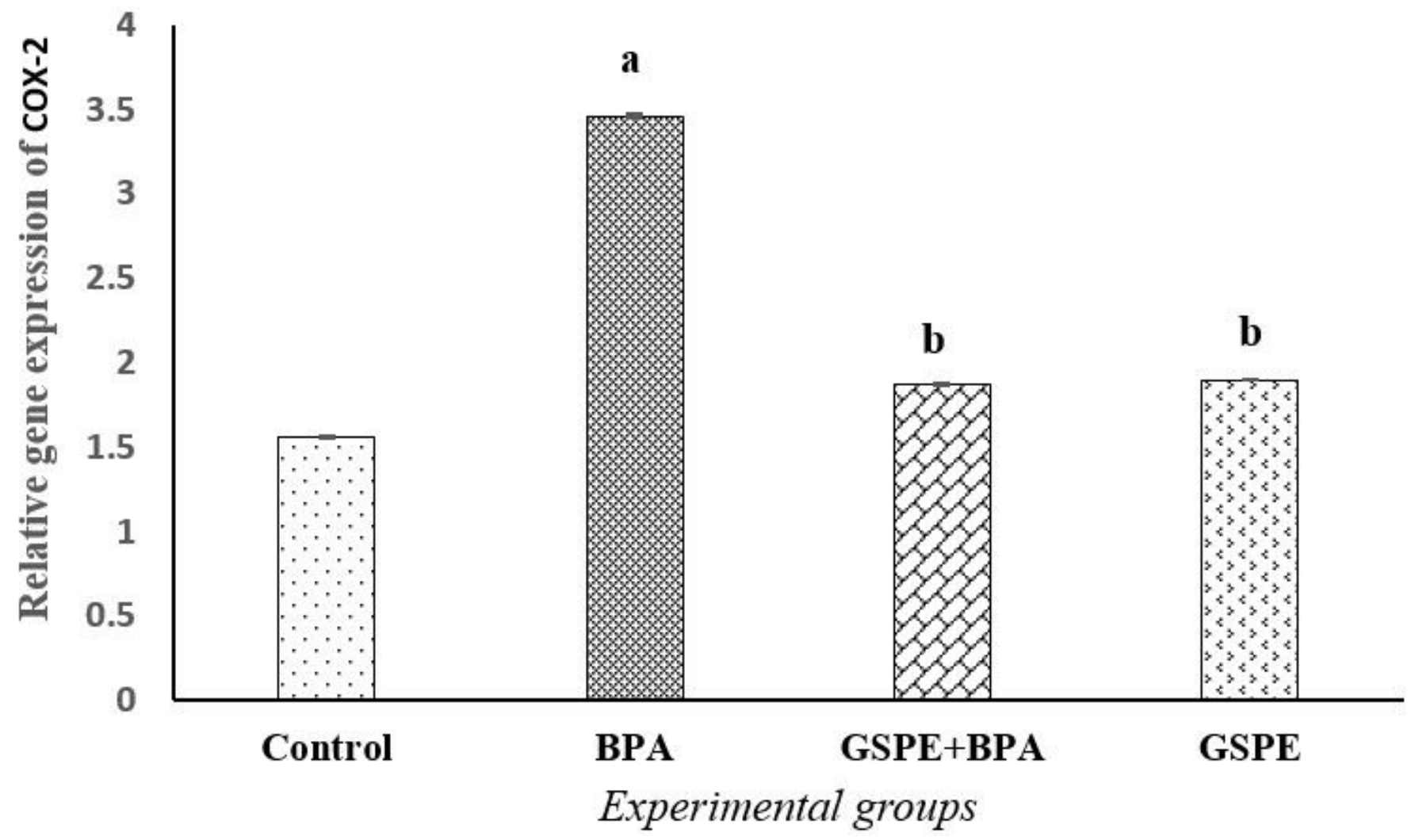

Figure 5

Effect of treatments on relative gene expression level of COX-2 in brain tissues of rats in different experimental group. $\beta$-actin serves as internal control. All the data were analyzed using one-way ANOVA followed by LSD test. Values are expressed as means of 7 rats \pm SE as compared to control group (a), BPA-treated group (b) at $\mathrm{P}<0.05$. 


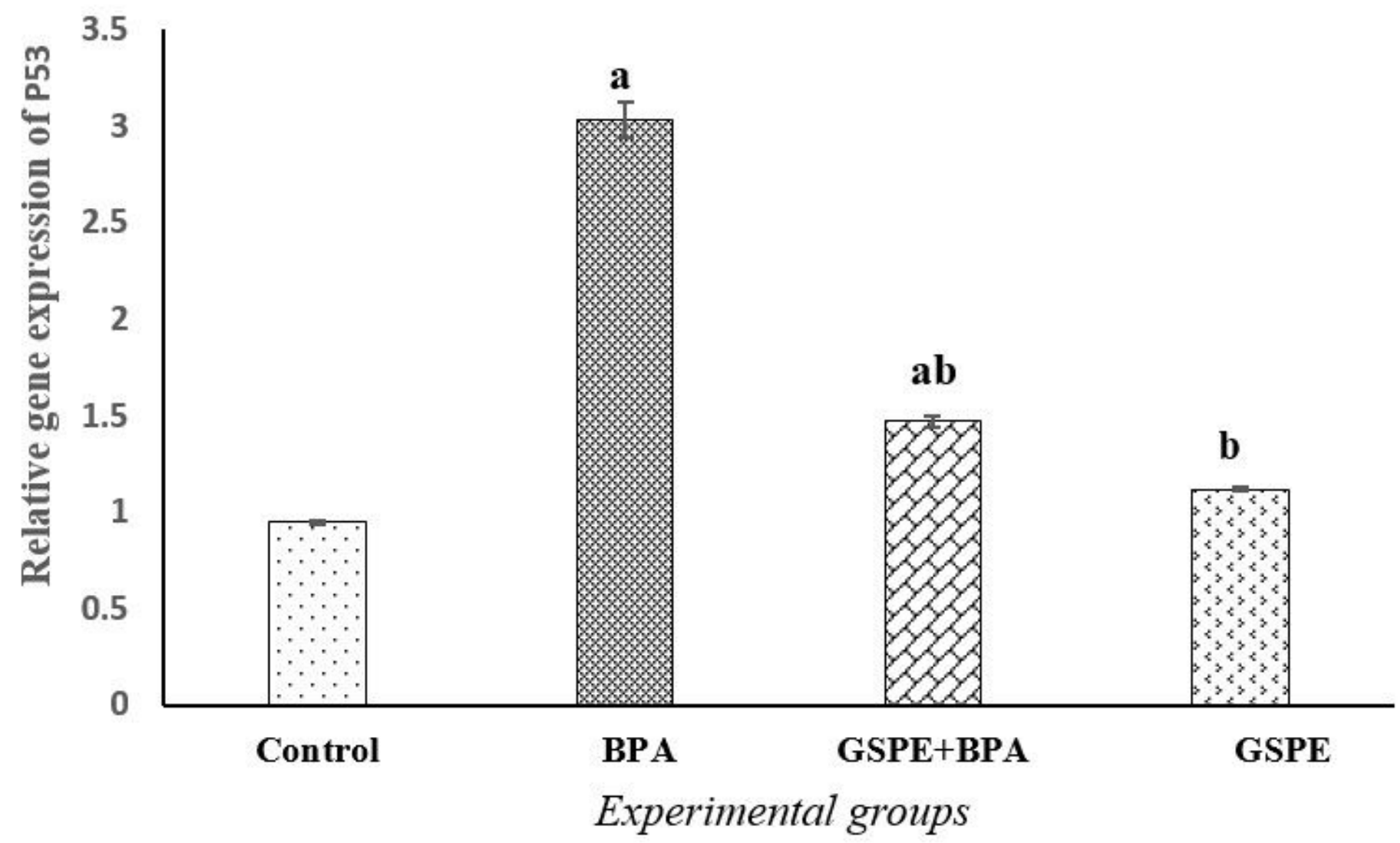

Figure 6

Effect of treatments on relative gene expression level of p53 in brain tissues of rats in different experimental group. $\beta$-actin serves as the internal control. All the data were analyzed using one-way ANOVA followed by LSD test. Values are expressed as means of 7 rats \pm SE as compared to control group (a), BPA-treated group (b) at $\mathrm{P}<0.05$.

\section{Supplementary Files}

This is a list of supplementary files associated with this preprint. Click to download.

- Graphicalabstarct.jpg 